\title{
Broadscale interseismic deformation and fault slip rates in the central Tibetan Plateau observed using InSAR
}

\author{
Matthew C. Garthwaite, ${ }^{1}$ Hua Wang, ${ }^{1,2,3}$ and Tim J. Wright ${ }^{1}$ \\ Received 7 May 2013; revised 5 August 2013; accepted 17 August 2013; published 17 September 2013.
}

[1] Knowledge of the number, location, and interseismic slip rate of crustal faults is key to our understanding of the bulk mechanics of continental deformation. However, at present, the sparsity of geodetic velocity observations is a major limiting factor to improving our knowledge of the fault network. In this study, we combine long-swath interferometric synthetic aperture radar (InSAR) data to form an interseismic displacement rate map of over $1000 \mathrm{~km}$ length spanning the central Tibetan Plateau. Our dense geodetic observations indicate that strain varies smoothly in space without major concentration at previously mapped faults. Discrepancy between line-of-sight InSAR and GPS observations between $33^{\circ} \mathrm{N}-35^{\circ} \mathrm{N}$ could indicate $\sim 4 \mathrm{~mm} / \mathrm{yr}$ of surface uplift in this region. Derived strain rates are less than $5 \times 10^{-8} \mathrm{yr}^{-1}$ across the plateau. At the E-W left-lateral Kunlun fault, postseismic deformation following the 2001 Kokoxili earthquake results in an observed strain rate of $18 \pm 4 \times 10^{-8} \mathrm{yr}^{-1}$ across a $100 \mathrm{~km}$ wide zone. Following removal of a viscoelastic model, we estimate an interseismic slip rate of $12 \pm 2 \mathrm{~mm} / \mathrm{yr}$ for the Kunlun fault. In the central Tibetan conjugate fault zone, the NE-SW striking Amdo-Sewa and NW-SE striking Beng Co faults have right-lateral slip rates of $6 \pm 1 \mathrm{~mm} / \mathrm{yr}$ and $1-4 \pm 1 \mathrm{~mm} / \mathrm{yr}$, respectively. Meanwhile, the NE-SW striking Dongqiao fault has a left-lateral slip rate of $1-2 \pm 1 \mathrm{~mm} / \mathrm{yr}$. The low slip rates we estimate for these faults indicate that tectonic strain is more broadly distributed across the plateau interior, perhaps due to the lithosphere being weak and without the abrupt strength contrasts that exist at the plateau margins.

Citation: Garthwaite, M. C., H. Wang, and T. J. Wright (2013), Broadscale interseismic deformation and fault slip rates in the central Tibetan Plateau observed using InSAR, J. Geophys. Res. Solid Earth, 118, 5071-5083, doi:10.1002/jgrb.50348.

\section{Introduction}

[2] The collision of the Indian and Eurasian continents is accommodated in the brittle crust of the high Tibetan Plateau by a distributed network of normal and strike-slip faults [Molnar and Tapponnier, 1978; Armijo et al., 1986, 1989; Taylor et al., 2003] (Figure 1a). Despite over 35 years of work, it is not clear how many faults are actively involved in accommodating strain in the Tibetan crust. Furthermore, the net Quaternary slip and the current interseismic slip rates of the known faults remain poorly known.

Additional supporting information may be found in the online version of this article.

${ }^{1}$ COMET + , School of Earth and Environment, University of Leeds, Leeds, UK.

${ }^{2}$ Department of Surveying Engineering, Guangdong University of Technology, Guangzhou, China.

${ }^{3}$ State Key Laboratory of Earthquake Dynamics, Institute of Geology, China Earthquake Administration, Beijing, China.

Corresponding author: M. C. Garthwaite, Geoscience Australia, Cnr Jerrabomberra Avenue and Hindmarsh Drive, Symonston, GPO Box 378 Canberra, ACT 2601, Australia. (Matt.Garthwaite@ga.gov.au)

(C)2013. American Geophysical Union. All Rights Reserved. 2169-9313/13/10.1002/jgrb.50348
[3] Major strike-slip faults in Tibet include the left-lateral Altyn Tagh, Kunlun, and Xianshuihe faults, and the rightlateral Karakoram fault [Molnar and Tapponnier, 1975]. It has been suggested that these strike-slip faults have accommodated the majority of strain within the Tibetan Plateau by allowing for the translation of coherent crustal blocks away from the collision zone [e.g., Tapponnier et al., 1982; Avouac and Tapponnier, 1993].

[4] Normal faulting on N-S striking rifts occurs throughout the southern plateau, south of the Jinsha suture (Figure 1a). Geologic evidence implies that these are the most recent structural elements in the Tibetan Plateau [Molnar and Tapponnier, 1978; Armijo et al., 1986], with seismic moment summations indicating that $15 \%-20 \%$ of the total E-W extensional strain is being accommodated by normal faulting in the present day [Elliott et al., 2010].

[5] In the central plateau, Armijo et al. [1989] mapped an en échelon array of NW-SE striking right-lateral faults; the Gyaring Co, Beng Co, and Jiali faults. These faults can be seen to truncate the N-S striking rifts in the terrane south of the Bangong-Nujiang suture (Figure 1a). The en échelon array was initially inferred to act as a conjugate to the Altyn Tagh and Kunlun faults, together accommodating eastward extrusion of Tibetan lithosphere from the collision zone [Armijo et al., 1989]. However, conjugate NE-SW striking 


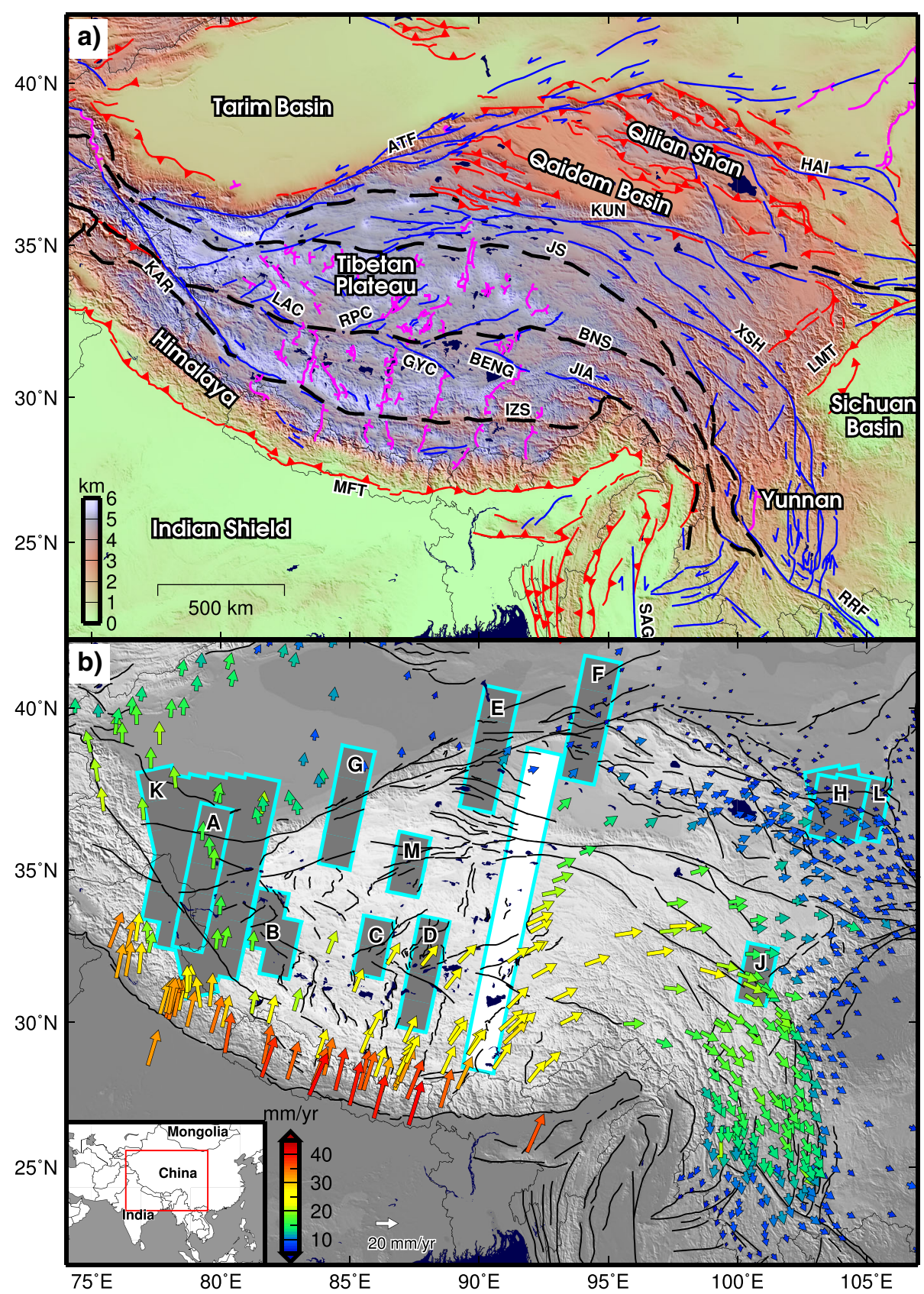

Figure 1. (a) Topographic map of the Tibetan Plateau and surrounding region with Quaternary active faults and geological sutures from the compilation of Taylor and Yin [2009]. Dashed black lines are geological sutures, red lines are thrust faults, blue lines are strike-slip faults, and magenta lines are normal faults. Symbols on faults indicate sense of movement with ticks on the hanging wall for normal faults and barbs on the upper plate for thrust faults. Name abbreviations for major features as follows: ATF, Altyn Tagh fault; BENG, Beng Co fault; BNS, Bangong-Nujiang Suture; GYC, Gyaring Co fault; HAI, Haiyuan ault; IZS, Indus-Zangbo Suture; JIA, Jiali fault; JS, Jinsha Suture; KAR, Karakoram fault; KUN, Kunlun fault; LAC, Lamu Co fault; LMT, Longmen Shan Thrust; MFT, Main Frontal Thrust; RPC, Riganpei Co fault; RRF, Red River fault; SAG, Sagaing fault; XSH, Xianshuihe fault. (b) Map showing the distribution of published InSAR studies of interseismic deformation in Tibet. Grey polygons with blue outlines show the spatial extent of synthetic aperture radar (SAR) data used in each study. See Table 1 for the citations relating to each lettered polygon. The spatial extent of data used in this study is highlighted by the white polygon with blue outline. Arrows are horizontal-component GPS velocity vectors relative to stable Eurasia from Gan et al. [2007]. The tail of each arrow is plotted at the measurement location with color representing absolute velocity magnitude. Black lines are active faults compiled by Taylor and Yin [2009]. Both maps are plotted in Mercator projection. Inset map: red box shows the extent of central Asia plotted. 


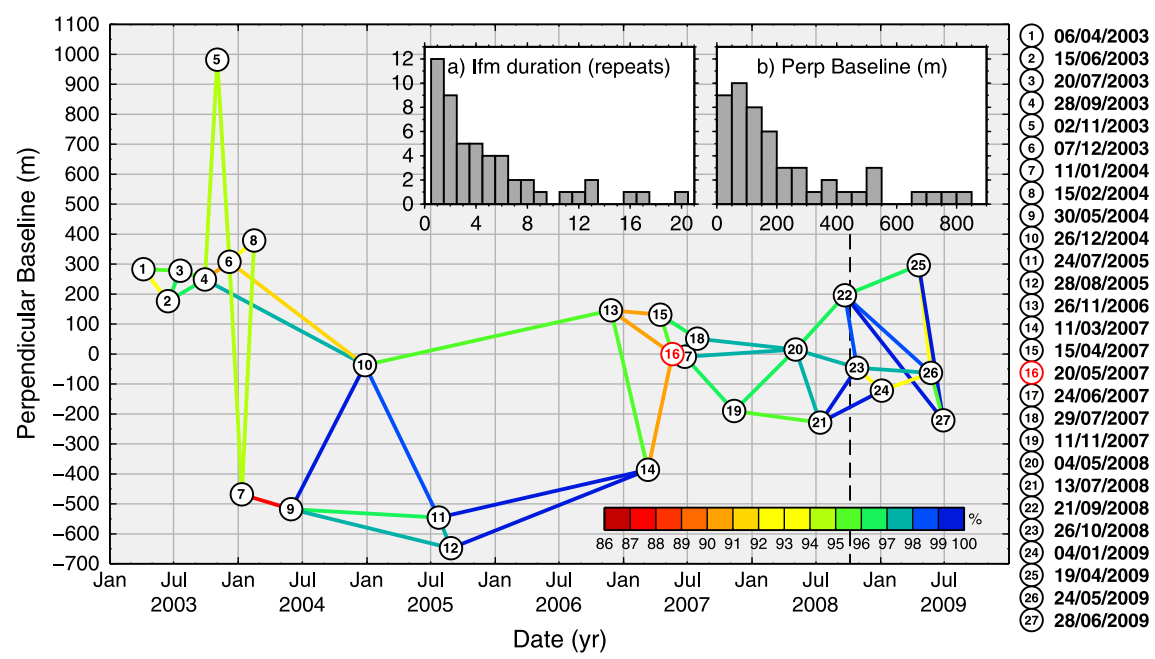

Figure 2. Baseline-time plot showing the network of 51 interferograms linking 27 ENVISAT SAR acquisitions. Lines represent the processed interferograms, which are colored according to the percentage of coherent pixels normalized to the most coherent interferogram (30 May 2004 to 26 December 2004). The vertical dashed line marks the occurrence time of the 6 October 2008 Damxung earthquake in south Tibet. Listed on the right are the dates of the 27 ENVISAT SAR acquisitions used, indicated by numbered circles in the plot. The red circle indicates the master SAR acquisition. Inset (a) histogram of interferogram time spans in terms of number of repeat orbits between master and slave acquisitions. ENVISAT had a minimum 35 day orbital repeat. Inset (b) histogram of interferogram differential perpendicular baselines. Refer to "supporting information Table S1" for further information on the 51 interferograms.

left-lateral faults were mapped directly to the north of the Bangong-Nujiang suture that pair with the NW-SE striking right-lateral faults. The so-called central Tibetan conjugate fault zone (CTCFZ) was estimated to accommodate concurrent N-S shortening on the order of 1-2 $\mathrm{mm} / \mathrm{yr}$ and $\mathrm{E}-\mathrm{W}$ extension of 2-4 mm/yr [Taylor et al., 2003].

[6] A common approach of interpreting a kinematic deformation field is to use geodetic observations, such as those obtained from Global Positioning System (GPS) data [e.g., Gan et al., 2007] (Figure 1b), to solve for the angular velocities of a finite number of "quasi-rigid blocks." If there are only a few large blocks, the strain must be accommodated by a small number of fast-slipping faults. As the number of blocks increases, more faults (with lower slip rates) are required to collectively accommodate the same strain. Where the geodetic observations are dense, the length scale of blocks is required to be on the order of the crustal thickness to reduce velocity residuals (e.g., in Southern California [Meade and Hager, 2005] or the Basin and Range [Hammond et al., 2011]). However, where geodetic observations are sparse, it is difficult to constrain a geometry of small blocks and assign strain to individual faults.

[7] In Tibet, Thatcher [2007] and Meade [2007] mostly used mapped fault structures to define their block boundaries, but the sparse GPS observations in the central and western parts of the plateau (Figure 1b) prevent them from modeling smaller blocks. As a consequence, significant strain accumulation occurs along block boundaries where there is no evidence for such high strain rates. In an alternative view, continental deformation is interpreted as a viscous continuum that produces low surface strain gradients across large distances, and in which faults are passive markers that move with crustal blocks above a deforming continuum beneath [e.g., England and Houseman, 1986; Flesch et al., 2001; England and Molnar, 2005]. Although the reality of continental deformation probably sits somewhere between the extremes of block kinematics and viscous continuum, it is clear that high-resolution geodetic velocity observations are key to revealing the mechanism of present-day deformation in Tibet.

[8] Interferometric synthetic aperture radar (InSAR) is a geodetic remote-sensing method that makes use of repeatpass satellite radar imagery to measure surface displacements over large land areas at a dense spatial resolution [Bürgmann et al., 2000; Rosen et al., 2000]. Over the last decade, InSAR has been demonstrated to be capable of measuring low-strain tectonic deformation at the level of a few millimeters per year by using multiple interferograms to increase the signal-to-noise ratio [e.g., Wright et al., 2001; Peltzer et al., 2001; Wright et al., 2004]. In this study, we use InSAR to vastly increase the number of geodetic observations in central Tibet compared with GPS alone. We have produced a displacement rate (velocity) map of over $1000 \mathrm{~km}$ length and used it to observe broadscale deformation trends and place constraints on the slip rates of the strike-slip faults in central Tibet.

\section{InSAR Data and Processing}

[9] We used synthetic aperture radar (SAR) data from the European Space Agency (ESA) ENVISAT satellite in this study. We chose descending track 176 since a reasonable data archive covering the full N-S extent of the plateau was available. Track 176 also has the advantage of being in close proximity to a N-S profile of campaign GPS stations [Gan et al., 2007] (Figure 1b). Twenty-seven 
SAR acquisitions (Figure 2) in image mode were chosen that fully cover the region between the latitudes $28.5^{\circ} \mathrm{N}$ to $38.5^{\circ} \mathrm{N}$. This scene covers a N-S distance of $\sim 1100 \mathrm{~km}$ corresponding to 11 standard ENVISAT frames. The 27 acquisitions used cover an observation period of $\sim 6.22$ years (2275 days or 65 ENVISAT repeat orbit cycles). All acquisitions are vertically polarized and collected in swath mode IS2, corresponding to incidence angles of between $19.2^{\circ}$ at near range and $26.7^{\circ}$ at far range (giving a mean of $\sim 23^{\circ}$ ).

[10] We processed a network of 51 interferograms using the GAMMA SAR processor and interferometry software (Figure 2 and "supporting information Table S1"). Although distributions of spatial and temporal baselines (histograms in Figure 2) are skewed toward lower baseline values, it was necessary to form some interferograms with long baselines to connect in as many acquisitions as possible and also link the early and late parts of the network. We chose a single master acquisition (20 May 2007) and aligned all the other SAR acquisitions to the geometry of this master before forming the interferograms. We used a 3 arc-second Shuttle Radar Topography Mission digital elevation model (DEM) [Farr et al., 2007 ] and DORIS (doppler orbitography and radio-positioning integrated by satellite) precise state vectors to flatten each interferogram. We applied an adaptive power spectrum filter [Goldstein and Werner, 1998] to reduce the phase noise in the interferograms before phase unwrapping with the minimum cost flow algorithm [Costantini, 1998]. The interferograms were manually checked for unwrapping errors using a phase closure technique [Biggs et al., 2007].

\section{InSAR Rate Map Estimation}

[11] The observed phase in the processed interferograms $\left(\phi_{\text {int }}\right)$ results from the summation of several signal components:

$$
\phi_{\mathrm{int}}=\phi_{\mathrm{def}}+\phi_{\mathrm{orb}}+\phi_{\mathrm{atm}}+\phi_{\mathrm{other}}
$$

where $\phi_{\text {def }}$ is the deformation signal of interest, $\phi_{\text {orb }}$ is a residual signal associated with the orbital geometry, $\phi_{\text {atm }}$ is an atmospheric phase delay signal, and $\phi_{\text {other }}$ is any other sources of noise (e.g., unwrapping errors, DEM errors, decorrelation noise, instrument noise, and filter noise). In the following sections, we describe how we estimate and remove the effects of coseismic and postseismic deformation phenomena and the nuisance signals $\phi_{\text {orb }}$ and $\phi_{\text {atm }}$, before estimating the linear displacement rate map using the stacking algorithm implemented in the Poly-Interferogram Rate and Time-series Estimator $(\pi-R A T E)$ software [Wang et al., 2012].

\subsection{Coseismic and Postseismic Signals}

[12] Since the main aim of our study is to quantify interseismic deformation, coseismic, or postseismic signals represent an additional source of noise. Lohman and Simons [2005] and Dawson et al. [2008] find that coseismic signals from earthquakes as small as $\sim M_{w} 4.5$ can be detected using InSAR, providing that the depth is shallow $(<5 \mathrm{~km})$. Thus, earthquakes of this size or greater may appear in interferograms spanning the earthquake date.

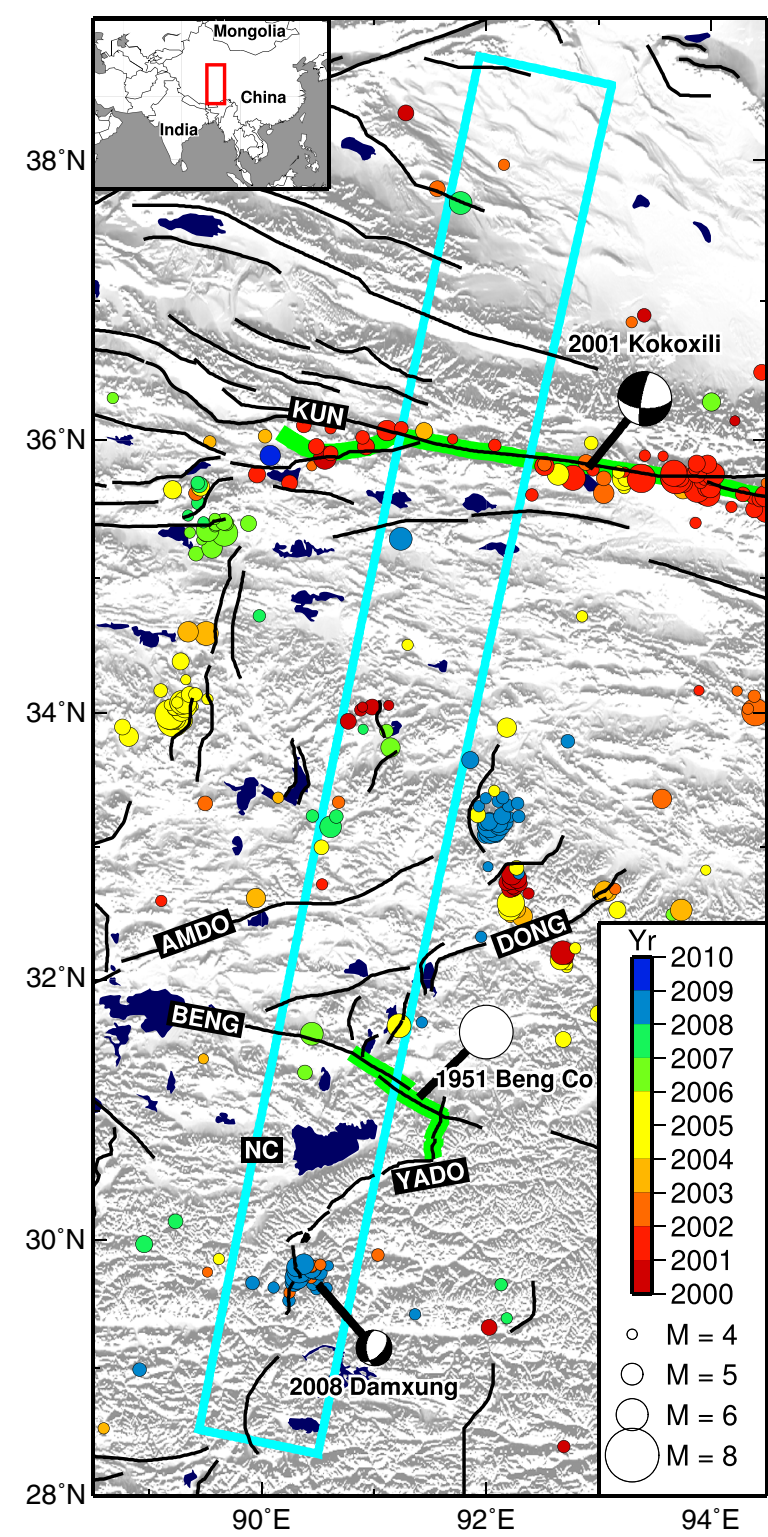

Figure 3. Seismicity in the region of the SAR scene during the period 1 January 2000 to 29 June 2009. Earthquakes between $4 \leq M<6$ are plotted as circles and colored according to the year of occurrence. Earthquakes with $M \geq 6$ are named and plotted as double couple moment tensors, except for the 1951 Beng Co earthquake for which this information is not available. Plotted events are shallower than $70 \mathrm{~km}$ depth and symbol diameter scales with earthquake magnitude. The blue rectangle delineates the location of SAR data used in this study. Black lines are active faults compiled by Taylor and Yin [2009]. Labels are as follows: KUN, Kunlun fault; AMDO, Amdo-Sewa fault; DONG, Dongqiao fault; BENG, Beng Co fault; NC, Lake Nam Co; YADO, Yadong-Gulu rift. The surface ruptures of the 2001 Kokoxili earthquake on the Kunlun fault [Lasserre et al., 2005] and the 1951 earthquake on the Beng Co fault [Armijo et al., 1989] are marked by thick green lines. Earthquake locations from Incorporated Research Institutions for Seismology (IRIS) database and moment tensors from the Global Centroid Moment Tensor project. Mercator projection. Inset map: red box shows the extent of central Asia plotted. 


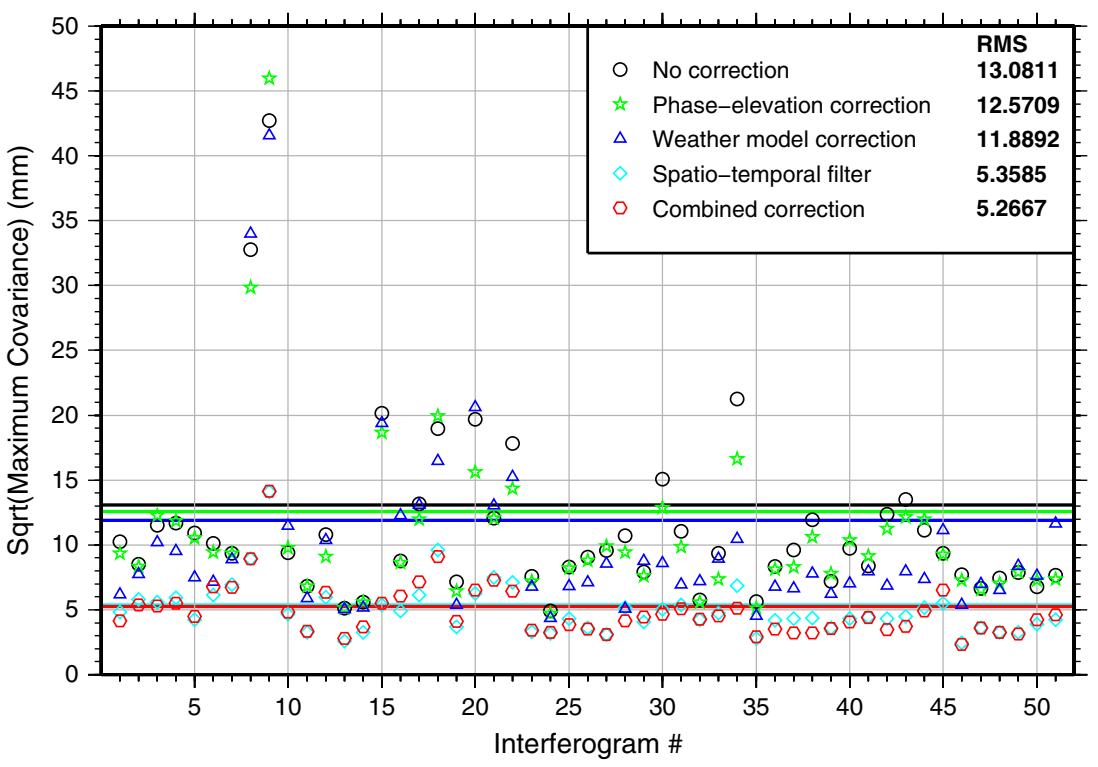

Figure 4. Square-root of the estimated maximum covariance of the interferograms (i.e., standard deviation) following atmospheric phase delay correction using the three methods described in the text. Colored horizontal lines indicate the RMS values for each method, with values given in the legend. Refer to "supporting information Table S1" for more information on each numbered interferogram.

[13] In the immediate region of the SAR scene, we observe swarms of $M>4$ earthquakes clustered in time (Figure 3). Several swarms have occurred on the N-S striking rift systems, including the Yadong-Gulu rift south of Lake Nam Co and in the central region between the CTCFZ and the Kunlun fault. We checked the interferograms in detail but did not find any signal due to these earthquake swarms.

[14] The $M_{w} 6.3$ Damxung normal faulting earthquake occurred on the Yadong-Gulu rift in south Tibet on 6 October 2008 and directly within the SAR scene (Figure 3). The magnitude of coseismic deformation from the earthquake was large enough that surface deformation is observable in interferograms spanning the earthquake [Elliott et al., 2010]. Although the spatial extent of coseismic deformation is small, we subtracted the best-fitting coseismic model of Elliott et al. [2010] from the seven interferograms that span the date of the earthquake. We observed a short period postseismic after-slip signal in the epicentral region of the Damxung earthquake, though the magnitude and spatial extent are small enough that we neglect it in the following discussion.

[15] The $M_{w} 7.8$ Kokoxili left-lateral strike-slip earthquake occurred on the Kunlun fault on 14 November 2001 [Lasserre et al., 2005], prior to the period of SAR data used here and to the east of track 176 (Figure 3). In addition, a large number of $M<6$ aftershocks have occurred on the Kunlun fault following the main earthquake. Ryder et al. [2011] modeled the ongoing postseismic deformation caused by the Kokoxili earthquake with constraint from GPS and InSAR and found a considerable transient signal around the Kunlun fault. We obtained the cumulative postseismic displacement at each SAR acquisition time using the model of Ryder et al. [2011]. We then used these displacement time steps to construct postseismic corrections for each interferogram.

\subsection{A Priori Velocity Model and Residual Orbit Correction}

[16] We estimate residual orbital errors for each SAR acquisition using a network approach and a quadratic model [e.g., Biggs et al., 2007]. Long wavelength components of deformation can be aliased and erroneously removed at this stage. To counteract this, we construct a plateau-wide velocity field from point horizontal-component velocity observations obtained by GPS [Gan et al., 2007], using the methods described in Wang and Wright [2012] ("supporting information Figure S1"). We scale this "a priori velocity model" by the interferometric time spans and subtract from the corresponding interferograms before the orbital correction is evaluated. We then add back the subtracted model signals following orbital error and atmosphere correction and prior to rate map estimation. By using the a priori velocity model, we tie the InSAR-derived rate map to a geodetic reference frame (in this case, the fixed-Eurasia frame relative to ITRF2000 used by Gan et al. [2007]).

\subsection{Atmospheric Phase Delay Signals}

[17] Several studies have noted a strong correlation between interferometric phase and topography [e.g., Taylor and Peltzer, 2006; Cavalié et al., 2008; Elliott et al., 2008]. This signal is attributed to the varying thickness of the tropospheric layer due to spatial variations of topography [Hanssen, 2001]. Phase returns from lower elevations are more susceptible to changes in the precipitable water vapor content between acquisitions because of the increased relative path length. Cavalié et al. [2008] and Elliott et al. [2008] used an empirical approach to estimate the best-fitting linear correlation between interferometric phase and elevation (phase-elevation correction).

[18] Jolivet et al. [2011] used the global ERA-Interim weather model from the European Center for Medium- 


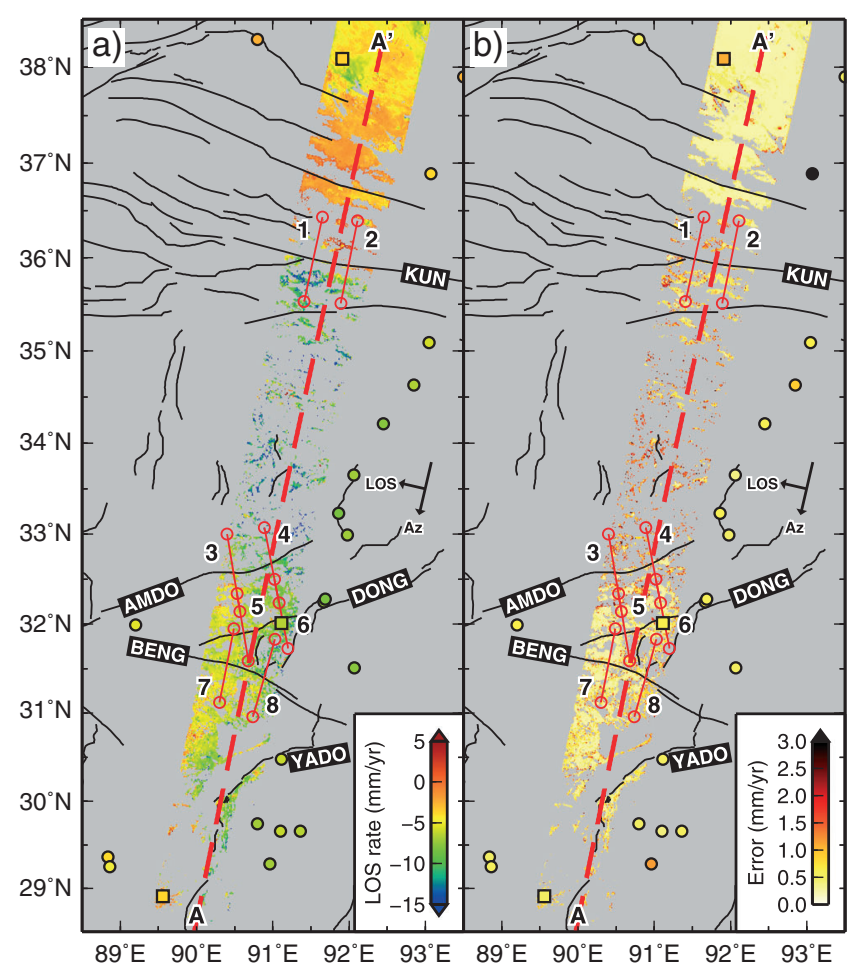

Figure 5. (a) Line-of-sight (LOS) InSAR rate map derived from the 49 interferogram network and (b) the associated error map. Each observation is the average pixel displacement rate calculated for the entire observation period (6.22 years), and negative rates indicate movement toward the satellite. Solid black lines are active faults compiled by Taylor and Yin [2009]. The strike-slip Kunlun, Amdo-Sewa, Dongqiao, and Beng Co faults are labeled KUN, AMDO, DONG, and BENG, respectively, and discussed further in the text. The Yadong-Gulu rift is labeled YADO. Dashed red line is the profile $\mathrm{A}-\mathrm{A}^{\prime}$ drawn in Figure 6. Numbered solid red lines with circular end markers indicate the individual fault profile locations drawn in Figure 8. Colored circles and squares in both maps show the location of GPS observations from Gan et al. [2007] with the horizontal-component velocities and 2-sigma errors mapped into the satellite LOS. The three observations plotted as squares are used to calculate the RMS difference between collocated GPS and InSAR rate pixels.

Range Weather Forecasts to determine the atmospheric delay close to the time (i.e., within a few hours) of each SAR acquisition. Their method estimates the phase-elevation relation at each grid node of the weather model and then interpolates this spatially and vertically to obtain a delay map for each SAR acquisition date. Due to the relatively coarse spatial resolution of the ERA-Interim model $(75 \mathrm{~km})$, only medium to long wavelength components of the atmospheric phase delay signal can be removed with this weather model correction method.

[19] To remove shorter wavelength atmospheric artifacts, a spatiotemporal filter can be used [Ferretti et al., 2001; Berardino et al., 2002]. This method assumes that the atmospheric phase delay signal is spatially correlated but temporally uncorrelated, unlike interseismic and postseismic deformation signals that pervade through time. Using the spatiotemporal filter strategy has been shown to significantly reduce the level of noise in interferograms [e.g., Gourmelen et al., 2010; Wang et al., 2012].

[20] Here we compare these three methods for mitigating InSAR atmospheric phase delay signals on our network of 51 interferograms. For all methods, we combine master and slave delays to obtain a correction for each interferogram that is then removed. Following correction, we compute the two-dimensional autocovariance of each interferogram by Fourier transformation. The maximum covariance of the interferogram is then the radial average of this autocovariance [Hanssen, 2001]. We find that a simple exponential function provides a good fit for most interferograms.

[21] From the estimated maximum covariances of the 51 interferograms and the root-mean-squared (RMS) maximum covariance, we find that the spatiotemporal filter method provides the best reduction in the atmospheric noise of any single method (Figure 4). A further marginal improvement is gained when using the weather model correction in combination with the spatiotemporal filter. For interferograms that cover large along-track distances such as used here, atmospheric conditions could vary considerably from one end of the scene to the other. In this situation, the method of Jolivet et al. [2011] gives a slight improvement over the empirical phase-elevation correction method that estimates a single linear correlation for the entire scene (Figure 4).

[22] Correlation coefficients between phase values corrected using the weather model versus the spatiotemporal filter have a mean of $\sim 0.3$ and a standard deviation of $\sim 0.1$ ("supporting information Figure S2"). This indicates that there are significant short wavelength atmospheric signals present in the SAR data that cannot be mitigated using current global weather models due to their relatively coarse resolution. Kinoshita et al. [2013] reach the same conclusion in a study using L-band SAR data from the Japanese ALOS satellite despite using local weather models with finer resolutions of $10 \mathrm{~km}$ and $1 \mathrm{~km}$.

[23] Following our analysis of atmospheric noise in the interferograms, we use only the spatiotemporal filter method in what follows. Furthermore, we remove interferograms \#8 and \#9 from the analysis since they are considerably noisier than the rest of the network (Figure 4 and "supporting information Figure S2"). Following orbital correction and spatiotemporal filtering, the reduced set of 49 interferograms has mean covariance of $18.5 \mathrm{~mm}^{2}$ and decay length scale of $6.0 \mathrm{~km}$, which is consistent with the values obtained in a smaller-scale InSAR study of the Xianshuihe fault [Wang et al., 2009].

\subsection{The $\pi$-RATE Stacking Algorithm}

[24] The stacking algorithm implemented in the $\pi-R A T E$ software determines the displacement rate (velocity) for a pixel even if it is not always coherent in the interferograms. We consider it important to include these pixels in the analysis in order to provide as much constraint on the rate as possible. Furthermore, this leads to a rate map with more velocity observations in regions that are challenging for interferometry. The stacking algorithm operates on a pixel-by-pixel basis and uses a minimum spanning tree method [Kruskal, 1956] to select a linearly independent network of observations for each pixel. By using the 


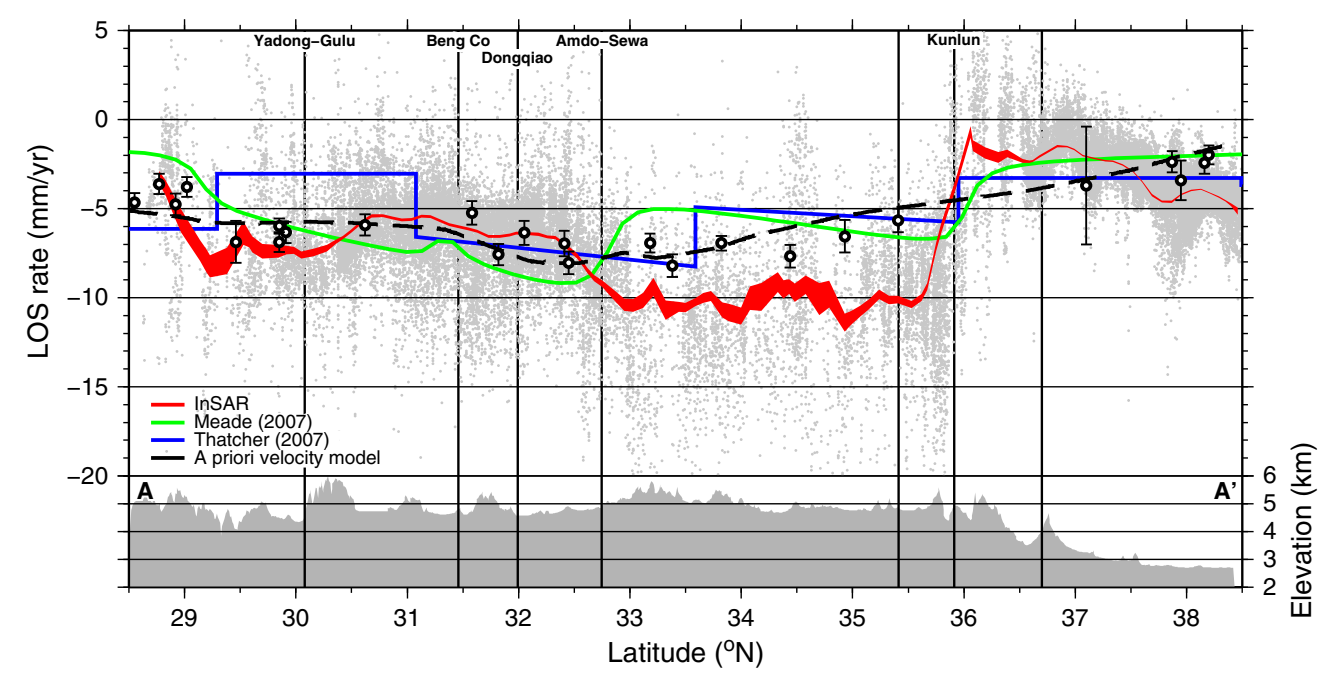

Figure 6. Along-track profile A-A' of the LOS InSAR rate map shown in Figure 5a. All coherent pixels in the rate map are extrapolated orthogonally onto the profile line and plotted as gray points. Each observation is the average pixel displacement rate calculated for the entire observation period (6.22 years), and negative rates indicate movement toward the satellite. Red polygon shows the 2-sigma error envelope of the mean LOS rate calculated using a moving average every $10 \mathrm{~km}$ with a bin width of $30 \mathrm{~km}$ along-track and encompassing all pixels across-track. In calculating the profile, pixels are weighted based on their distance from the profile line and rate map formal error value (Figure 5b). Dashed black line is a profile through the a priori velocity model used in $\pi-R A T E$ processing ("supporting information Figure S1"). Blue and green lines are coincident profiles through the block models of Thatcher [2007] and Meade [2007], respectively, converted into the LOS. Black circles with 2-sigma error bars are the LOS-converted GPS observations [Gan et al., 2007] plotted in Figure 5 projected perpendicularly on to the profile. Lower gray profile shows the topography along the profile line. Intersections of the profile line with faults from the Taylor and Yin [2009] compilation are marked by vertical black lines.

percentage of coherent pixels in each interferogram as the weight for each "tree" [e.g., Wang et al., 2012], interferograms with greater coherence prevail in constraining the rate. A weighted least squares inversion is used to determine the best-fitting rate and associated formal error at each pixel [e.g., Wang et al., 2012]. The inversion is weighted with a variance-covariance matrix that takes into account the temporal correlation between interferograms [Biggs et al., 2007]. We choose to exclude from the rate map any pixel that does not have 15 or more coherent observations. We then calculate the ratios between the residuals (interferometric observations minus evaluated rate) and the maximum covariance for that observation calculated previously. If any ratio is greater than 3 , the observation with the maximum ratio is removed and the rate is re-evaluated with one less observation. This procedure is repeated iteratively until all ratios are less than 3 , providing that the number of coherent observations for that pixel is still greater than or equal to 15 . Finally, if the formal error is greater than $3 \mathrm{~mm} / \mathrm{yr}$, the pixel is removed from the rate map.

\section{Tibetan Plateau Rate Map}

[25] We used the $\pi$-RATE methodology to estimate the linear rate map spanning over $1000 \mathrm{~km}$ across Tibet from our network of 49 interferograms (Figure 5). The RMS difference between those rate map pixels collocated with GPS observations is $0.992 \mathrm{~mm} / \mathrm{yr}$ in the satellite line-ofsight (LOS; locations marked by the three colored squares in Figure 5).
[26] We find that the most interferometrically coherent regions are situated in the Qaidam basin in the north of the rate map $\left(\sim 37^{\circ} \mathrm{N}\right)$ and around the CTCFZ toward the southern end of the rate map $\left(\sim 30.5^{\circ} \mathrm{N}\right)$. In these regions, the number of pixels in the rate map is high, the signal is smooth, and the formal errors are low. The least coherent regions are in the center and south of the rate map. Coherence is reduced south of the CTCFZ $\left(\sim 30.5^{\circ} \mathrm{N}\right)$ due to the increased relief leading up to the Himalayan crest with its associated steeper slopes and increased snow cover. Much of central Tibet between $32^{\circ} \mathrm{N}-36^{\circ} \mathrm{N}$ is classified as pervasive high-altitude permafrost [Cheng and $\mathrm{Wu}, 2007]$. Freeze-thaw cycles in the permafrost can cause temporal decorrelation of pixels in interferograms. As a result, the number of rate map pixels in this region is less, the estimated rates exhibit greater scatter, and the formal error is correspondingly higher.

[27] The most striking signal in the rate map is situated at the Kunlun fault. This signal has a left-lateral sense of strike-slip motion and a cross-fault magnitude of $\sim 8 \mathrm{~mm} / \mathrm{yr}$ in LOS, which is at least 2 times greater than the signal predicted by elastic block models [Meade, 2007; Thatcher, 2007] (Figure 6). The peak strain rate of the observed signal at the Kunlun fault is $18 \pm 4 \times 10^{-8} \mathrm{yr}^{-1}$. The Kokoxili postseismic deformation model of Ryder et al. [2011] closely matches this steep velocity gradient (Figure 7). Following removal of this postseismic model from the interferograms, the rate map shows a shallower velocity gradient without significant changes in gradient for a distance of approximately $200 \mathrm{~km}$ across the Kunlun fault (Figure 7). Across the 

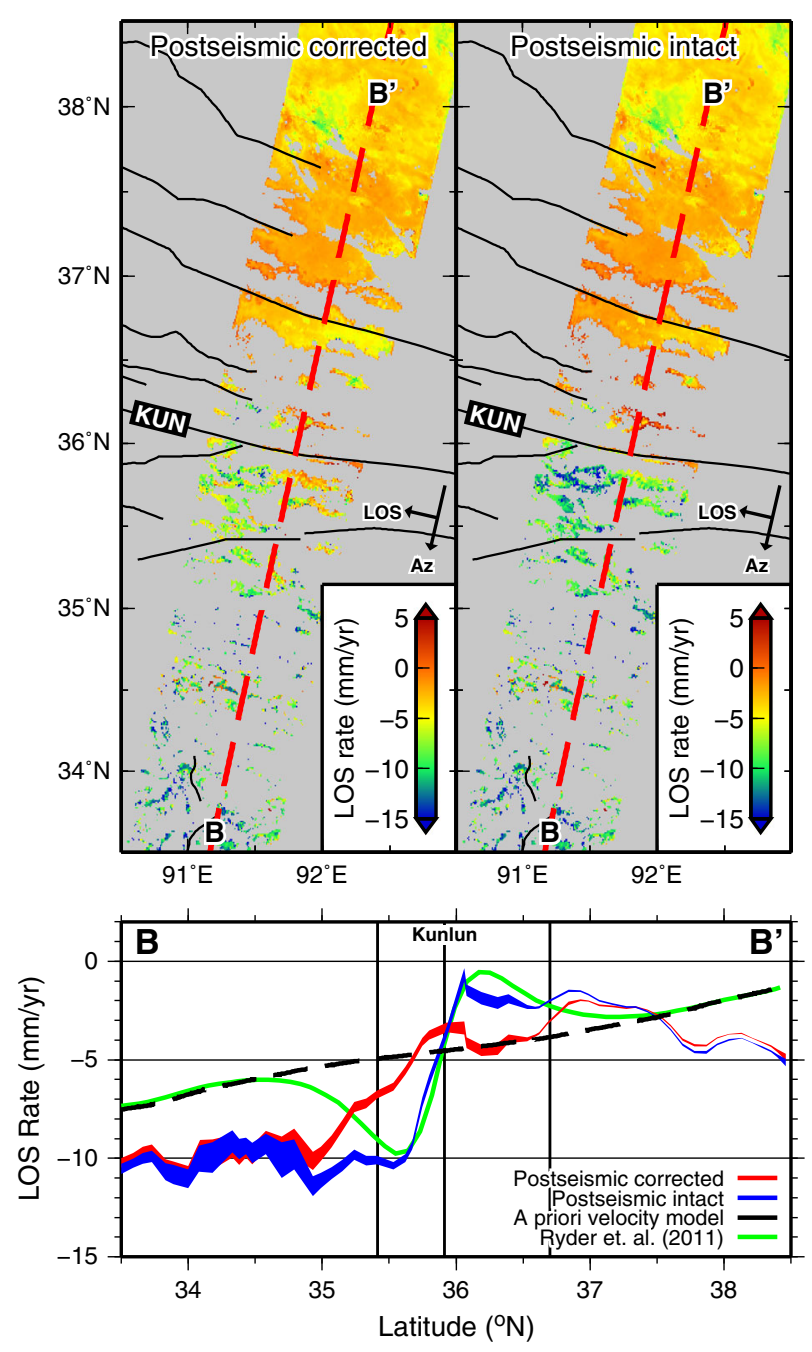

Figure 7. Comparison of a subsection of the InSAR LOS rate map around the Kunlun fault region with and without postseismic correction. Dashed red lines in rate maps indicate the location of profile B-B', drawn below. Red and blue polygons in the profile show the 2-sigma error envelope of the mean LOS rate calculated in the same way as in Figure 6 . The green line shows the average LOS rate during the 6.22 year observation period of the Ryder et al. [2011] postseismic model, calculated by passing the network of postseismic corrections for each interferogram through the $\pi-R A T E$ stacking algorithm. Dashed black line is a profile through the a priori velocity model ("supporting information Figure S1"). Intersections of the profile line with faults from the Taylor and Yin [2009] compilation are marked by vertical black lines.

rate map, strain rates estimated from the InSAR data over $100 \mathrm{~km}$ length scales are less than $5 \times 10^{-8} \mathrm{yr}^{-1}$, except at the Kunlun fault where the reduced strain rate is on the order of $6 \pm 2 \times 10^{-8} \mathrm{yr}^{-1}$. Making the postseismic correction results in a marginal improvement in the RMS difference between the collocated GPS observations and InSAR rate pixels to $0.975 \mathrm{~mm} / \mathrm{yr}$ in LOS.

[28] The LOS unit vector for a descending ENVISAT orbit and IS2 swath at $34^{\circ} \mathrm{N}$ (scene center) is $\hat{\mathbf{l}} \approx$ $[0.383,-0.078,0.921]$ for east, north and up components, respectively. From this vector, we can see that the viewing geometry is relatively insensitive to displacements oriented N-S, but most sensitive to vertical deformation. Since the data used to constrain the a priori velocity model only contain the horizontal components of velocity, deviations between the model and InSAR observations may indicate regions where vertical deformation is occurring. Between $32.5^{\circ} \mathrm{N}$ and $35.5^{\circ} \mathrm{N}$, there is a significant deviation of the InSAR and the a priori velocity model of up to $4 \mathrm{~mm} / \mathrm{yr}$ in LOS (Figure 6). This magnitude and polarity of LOS signal corresponds to $\sim 10.5 \mathrm{~mm} / \mathrm{yr}$ of additional eastward movement or $\sim 4.3 \mathrm{~mm} / \mathrm{yr}$ of vertical uplift over a large area. Since the pattern of observed horizontal GPS velocities seems well resolved, it is more conceivable that the InSAR deviation represents a vertical deformation. Preliminary vertical GPS velocities in the Tibetan Plateau [Freymueller et al., 2010] qualitatively show a pattern of uplift south of $\sim 30^{\circ} \mathrm{N}$ and north of $\sim 32^{\circ} \mathrm{N}$ but a band of subsidence between $\sim 30^{\circ} \mathrm{N}$ and $32^{\circ} \mathrm{N}$ coincident with the location of the CTCFZ. The polarities of deviations of the InSAR rate map from the a priori velocity model correlate with these observations south of the Kunlun fault zone at $\sim 36^{\circ} \mathrm{N}$ (Figure 6). Elsewhere in the rate map, the InSAR observations are consistent with the a priori velocity model and GPS measurements.

\section{Estimates of Fault Strike-Slip Rates}

[29] Several previous studies have estimated the interseismic slip rate of Tibetan strike-slip faults using InSAR observations [e.g., Wright et al., 2004; Taylor and Peltzer, 2006; Lasserre et al., 2007; Jolivet et al., 2008, 2012; Elliott et al., 2008; Cavalié et al., 2008; Wang et al., 2009; Bell et al., 2011; Wang and Wright, 2012] (Table 1 and Figure 1b). Here we estimate interseismic slip rates for the most significant strike-slip faults covered by our InSAR rate map (Figure 5): the E-W striking Kunlun fault, the NE-SW striking Amdo-Sewa and Dongqiao faults, and NW-SE Beng Co fault. The latter three faults are part of the CTCFZ described by Taylor et al. [2003]. The strike of all the covered faults falls within $30^{\circ}$ of the descending ENVISAT LOS vector, so we expect that the viewing geometry will be reasonably sensitive to interseismic displacements across these faults.

[30] We extract pixels from the InSAR rate map derived without the use of the a priori velocity model (in order to now ignore long wavelength deformation trends) in $20 \mathrm{~km}$ wide swaths that include pixels up to $50 \mathrm{~km}$ from the fault trace. Each LOS velocity observation is converted to a faultparallel velocity assuming purely horizontal motion (no vertical motion in the LOS) via the following relationship:

$$
V_{\text {fault }}=V_{\mathrm{LOS}} \cdot(\sin \theta \cdot \cos (\psi-\varphi))^{-1}
$$

where $\theta$ is the incidence angle for the pixel measured between the nadir and satellite looking vector for each pixel, $\psi$ is the horizontal azimuth of the looking vector, and $\varphi$ is the strike of the fault.

[31] First, we invert the observed across-fault velocities of all pixels that fall within $5 \mathrm{~km}$ of the fault trace using a weighted least squares inversion in order to determine the rate offset at the fault. Pixels are weighted by the inverse of the formal error on the rate estimate. The determined offset is then subtracted from all pixels in the profile, resulting in a zero rate in the region of the fault trace. Second, we use 
Table 1. Summary of Estimated Interseismic Fault Strike-Slip Rates in Tibet From Previous InSAR Studies and From Weighted Least Squares Inversion of Fault-Parallel Pixel Velocities From the InSAR-Derived Rate Map (Figure 5)

\begin{tabular}{|c|c|c|c|c|c|c|}
\hline Fault & $\begin{array}{l}\text { Sense of } \\
\text { Motion }^{\mathrm{a}}\end{array}$ & Longitude & $\begin{array}{l}\text { Slip Rate } \\
(\mathrm{mm} / \mathrm{yr})\end{array}$ & $\begin{array}{c}\text { Location } \\
\text { (Figure 1b) }\end{array}$ & $\begin{array}{c}\text { Profile } \\
\text { (Figure 8) }\end{array}$ & Study \\
\hline \multirow[t]{7}{*}{ Altyn Tagh } & \multirow[t]{7}{*}{$\mathrm{S}$} & $78^{\circ} \mathrm{E}$ & $1 \pm 2$ & $\mathrm{~K}$ & - & Wang and Wright [2012] \\
\hline & & $80^{\circ} \mathrm{E}$ & $5 \pm 5$ & A & - & Wright et al. [2004] \\
\hline & & $80^{\circ} \mathrm{E}$ & $2 \pm 2$ & $\mathrm{~K}$ & - & Wang and Wright [2012] \\
\hline & & $85^{\circ} \mathrm{E}$ & $11 \pm 5$ & $\mathrm{G}$ & - & Elliott et al. [2008] \\
\hline & & $90^{\circ} \mathrm{E}$ & $16 \pm 5$ & $\mathrm{E}$ & - & Lasserre et al. [2007] \\
\hline & & $94^{\circ} \mathrm{E}$ & $11 \pm 2$ & $\mathrm{~F}$ & - & Lasserre et al. [2007] \\
\hline & & $94^{\circ} \mathrm{E}$ & $7-9$ & $\mathrm{~F}$ & - & Jolivet et al. [2008] \\
\hline \multirow[t]{2}{*}{ Amdo-Sewa } & \multirow[t]{2}{*}{$\mathrm{D}$} & $90.5^{\circ} \mathrm{E}$ & $13 \pm 1$ & - & 3 & This study \\
\hline & & $91.0^{\circ} \mathrm{E}$ & $6 \pm 1$ & - & 4 & This study \\
\hline \multirow[t]{2}{*}{ Beng Co } & \multirow[t]{2}{*}{$\mathrm{D}$} & $90.4^{\circ} \mathrm{E}$ & $1 \pm 1$ & - & 7 & This study \\
\hline & & $90.9^{\circ} \mathrm{E}$ & $4 \pm 1$ & - & 8 & This study \\
\hline \multirow[t]{2}{*}{ Dongqiao } & \multirow[t]{2}{*}{$\mathrm{S}$} & $90.6^{\circ} \mathrm{E}$ & $1 \pm 1$ & - & 5 & This study \\
\hline & & $91.1^{\circ} \mathrm{E}$ & $2 \pm 1$ & - & 6 & This study \\
\hline Gyaring Co & $\mathrm{D}$ & $88^{\circ} \mathrm{E}$ & $12.3-14.5$ & $\mathrm{D}$ & - & Taylor and Peltzer [2006] \\
\hline \multirow[t]{2}{*}{ Haiyuan } & \multirow[t]{2}{*}{$\mathrm{S}$} & $104^{\circ} \mathrm{E}$ & $\sim 6$ & $\mathrm{H}$ & - & Cavalié et al. [2008] \\
\hline & & $104^{\circ} \mathrm{E}$ & $5-8$ & $\mathrm{~L}$ & - & Jolivet et al. [2012] \\
\hline \multirow[t]{5}{*}{ Karakoram } & \multirow[t]{5}{*}{$\mathrm{D}$} & $77^{\circ} \mathrm{E}$ & $1 \pm 2$ & $\mathrm{~K}$ & - & Wang and Wright [2012] \\
\hline & & $78^{\circ} \mathrm{E}$ & $3 \pm 2$ & $\mathrm{~K}$ & - & Wang and Wright [2012] \\
\hline & & $79^{\circ} \mathrm{E}$ & $1 \pm 3$ & A & - & Wright et al. [2004] \\
\hline & & $79^{\circ} \mathrm{E}$ & $6 \pm 1$ & $\mathrm{~K}$ & - & Wang and Wright [2012] \\
\hline & & $80^{\circ} \mathrm{E}$ & $1 \pm 1$ & $\mathrm{~K}$ & - & Wang and Wright [2012] \\
\hline \multirow[t]{2}{*}{ Kunlun } & \multirow[t]{2}{*}{$\mathrm{S}$} & $91.5^{\circ} \mathrm{E}$ & $11 \pm 1$ & - & 1 & This study \\
\hline & & $92.0^{\circ} \mathrm{E}$ & $12 \pm 2$ & - & 2 & This study \\
\hline Lamu Co & $\mathrm{D}$ & $82^{\circ} \mathrm{E}$ & $2.1-4.1$ & B & - & Taylor and Peltzer [2006] \\
\hline Manyi & $\mathrm{S}$ & $87^{\circ} \mathrm{E}$ & $3 \pm 2$ & M & - & Bell et al. [2011] \\
\hline Riganpei Co & $\mathrm{S}$ & $86^{\circ} \mathrm{E}$ & 6.6 & $\mathrm{C}$ & - & Taylor and Peltzer [2006] \\
\hline Xianshuihe & $\mathrm{S}$ & $105.5^{\circ} \mathrm{E}$ & $9-12$ & $\mathrm{~J}$ & - & Wang et al. [2009] \\
\hline
\end{tabular}

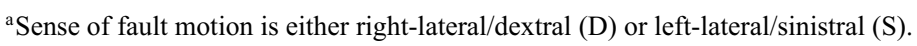

a weighted least squares approach to invert all the corrected across-fault pixel velocities to fit the interseismic fault slip rate in a locked-fault elastic dislocation model [e.g., Savage and Burford, 1973].

[32] We find that it is hard to constrain the locking depth parameter with only the InSAR rate map observations ("supporting information Figure S3"). Since focal depths for crustal earthquakes in the plateau interior fall between 5 and $10 \mathrm{~km}$ [e.g., Molnar and Chen, 1983], we assume a locking depth of $10 \mathrm{~km}$ for the slip rate inversions. Therefore, the only free model parameter in each inversion is the interseismic slip rate. For an elastic dislocation model with a locking depth of $10 \mathrm{~km}, \sim 87 \%$ of elastic strain is visible at a distance of $\pm 50 \mathrm{~km}$ from the fault trace, which is enough to characterize the steepest part of the velocity gradient.

\subsection{Kunlun Fault}

[33] Postseismic deformation from the Kokoxili earthquake manifests in our InSAR observations at the E-W striking left-lateral Kunlun fault. The estimated slip rate when this signal is present is $29 \pm 1 \mathrm{~mm} / \mathrm{yr}$ at $91.5^{\circ} \mathrm{E}$ and $36 \pm 1 \mathrm{~mm} / \mathrm{yr}$ at $92.0^{\circ} \mathrm{E}$ (profiles 1 and 2 , respectively, in Figure 8). These are remarkably high slip rates that cannot be attributed to interseismic deformation alone. Once we correct the data using the postseismic model of Ryder et al. [2011], the estimated interseismic slip rate of the Kunlun fault is $11 \pm 1 \mathrm{~mm} / \mathrm{yr}$ at $91.5^{\circ} \mathrm{E}$ and $12 \pm 2 \mathrm{~mm} / \mathrm{yr}$ at $92.0^{\circ} \mathrm{E}$. These latter estimates are consistent with previous estimates for the Kunlun fault summarized as $10 \pm 2 \mathrm{~mm} / \mathrm{yr}$ over its entire length [Molnar and Dayem, 2010].

\subsection{Amdo-Sewa Fault}

[34] In the fault compilation of Taylor and Yin [2009], the Amdo-Sewa fault is mapped as a NE-SW striking leftlateral fault that is the conjugate pair of the NW-SE striking Gyaring Co fault. However, our inversion for the AmdoSewa fault results in slip rates with a right-lateral sense of motion, which is inconsistent with the overall kinematics of the CTCFZ. We estimate a slip rate of $13 \pm 1 \mathrm{~mm} / \mathrm{yr}$ at $90.5^{\circ} \mathrm{E}$ and $6 \pm 1 \mathrm{~mm} / \mathrm{yr}$ at $91.0^{\circ} \mathrm{E}$ (profiles 3 and 4 , respectively, in Figure 8). In the western of the two profiles, the slip rate seems to be overestimated due to a patch of outliers in the observations $\sim 40 \mathrm{~km}$ north of the fault trace (as shown by the moving average line in profile 3 ). Therefore, the slip rate estimate of $6 \pm 1 \mathrm{~mm} / \mathrm{yr}$ appears better-constrained.

\subsection{Dongqiao Fault}

[35] The NE-SW striking left-lateral Dongqiao fault is the conjugate pair of the NW-SE striking Beng Co fault. We estimate its slip rate as $1 \pm 1 \mathrm{~mm} / \mathrm{yr}$ at $90.6^{\circ} \mathrm{E}$ and $2 \pm 1 \mathrm{~mm} / \mathrm{yr}$ at $91.1^{\circ} \mathrm{E}$ consistent with the mapped left-lateral sense of motion (for profiles 5 and 6, respectively, in Figure 8). Although the estimated slip rates are low, the arctangent form of the elastic dislocation model does not resemble the trend of the observations across the fault. The slip rate of the Dongqiao fault may be too low to be resolvable with InSAR (i.e., $<1 \mathrm{~mm} / \mathrm{yr}$ ).

\subsection{Beng Co Fault}

[36] The Beng Co fault is a NW-SE striking right-lateral fault forming one segment of the aforementioned en échelon array of NW-SE striking faults. Armijo et al. [1989] mapped 

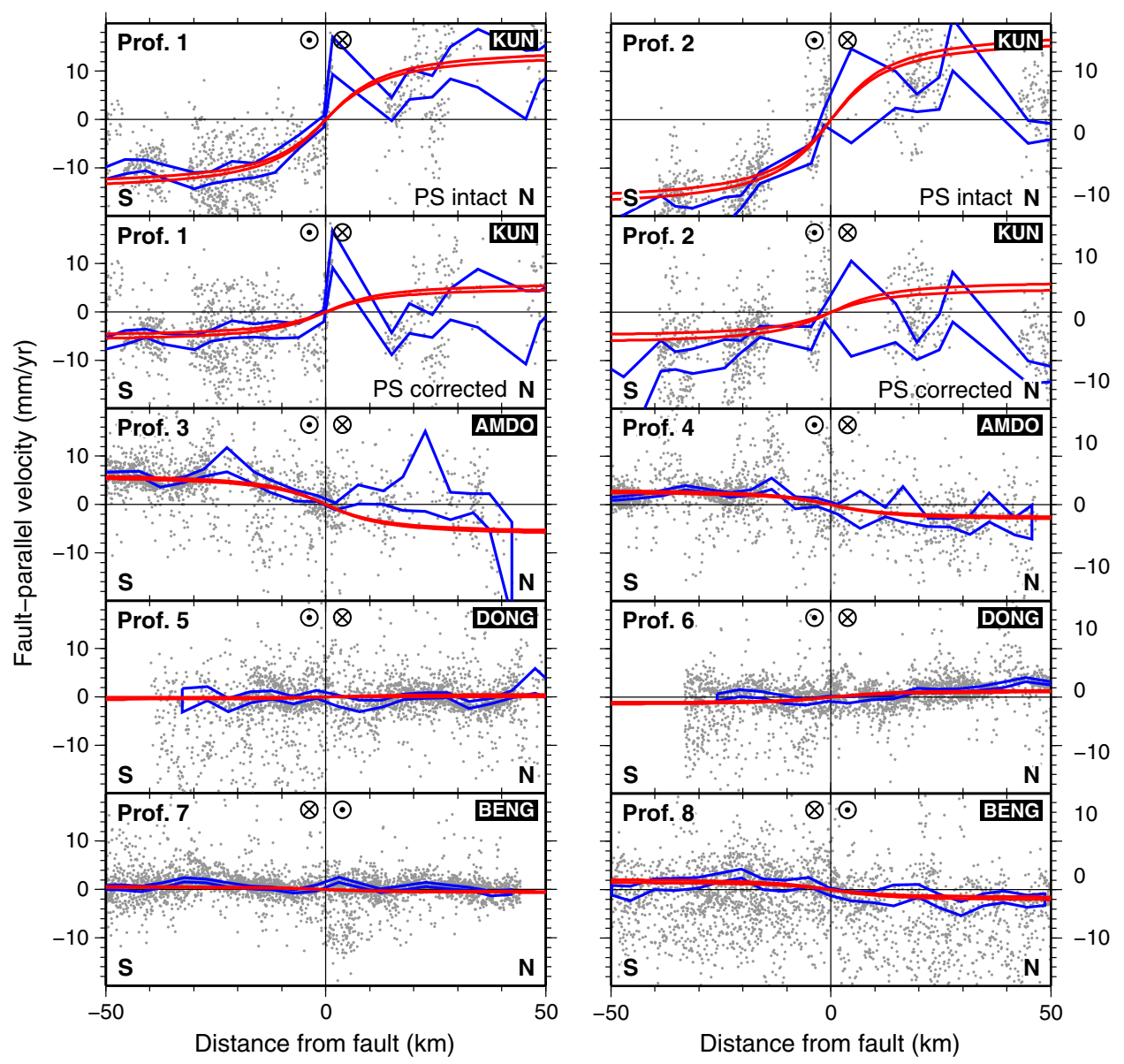

Figure 8. Fault-perpendicular profiles for the Kunlun (KUN), Amdo-Sewa (AMDO), Dongqiao (DONG), and Beng Co (BENG) strike-slip faults. Grey points indicate pixel observations from the InSAR rate map (Figure 5) within $20 \mathrm{~km}$ distance of the profile line converted to fault-parallel rates (i.e., horizontal motion only) and normalized to zero at the fault trace as described in the text. Each observation is the average pixel displacement rate calculated for the entire observation period ( 6.22 years). The blue polygon shows the 2-sigma error envelope of the mean rate calculated in $5 \mathrm{~km}$ bins along profile. The red polygon shows the estimated 2-sigma error envelope on the strike-slip rate for an elastic dislocation model with a locking depth of $10 \mathrm{~km}$. Strike-slip fault symbols indicate the mapped sense of motion as given by Taylor and Yin [2009]. Locations of the numbered profiles are shown in Figure 5.

the surface rupture of an $M_{S} 8$ right-lateral strike-slip earthquake that occurred on the Beng Co fault on 18 November 1951, to the east of the SAR scene used here (Figure 3). Since a viscoelastic model of the Kokoxili earthquake postseismic deformation predicts significant surface deformation even 50 years post-earthquake, the similarly sized Beng Co earthquake may be causing significant postseismic deformation at the present day in the region of the SAR scene. We estimate right-lateral slip rates of $1 \pm 1 \mathrm{~mm} / \mathrm{yr}$ at $90.4^{\circ} \mathrm{E}$ and $4 \pm 1 \mathrm{~mm} / \mathrm{yr}$ at $90.9^{\circ} \mathrm{E}$ (profiles 7 and 8 , respectively, in Figure 8). The observations in the western profile exhibit very low noise and low magnitude fluctuations around zero, suggesting that the Beng Co fault is not accumulating strain in this locality. However, the observations on the eastern profile are more consistent with the arctangent form of an elastic dislocation model, yet exhibit higher scatter. This could indicate that the signal we observe in the eastern profile is not interseismic in origin, but instead associated with the 1951 earthquake.

\section{Discussion}

[37] Our InSAR observations are consistent with low slip rates $\leq 6 \mathrm{~mm} / \mathrm{yr}$ for strike-slip faults in the CTCFZ (Table 1). Taylor and Peltzer [2006] used long-temporal baseline SAR interferograms to infer low slip rates of $2-4$ and $7 \mathrm{~mm} / \mathrm{yr}$ for the NW-SE right-lateral Lamu Co and the NE-SW leftlateral Riganpei Co fault, respectively (both also part of the CTCFZ). However, they found the Gyaring Co fault to have a faster slip rate of $12-15 \mathrm{~mm} / \mathrm{yr}$ (Figure 1 and Table 1). Reported error bounds on these estimates are high since analysis was made on single interferograms. It seems likely therefore that the high slip rate on the Gyaring Co fault is not representative of other faults in the en échelon array, such as the Beng Co fault directly to the east that we find has a slip rate of $1-4 \pm 1 \mathrm{~mm} / \mathrm{yr}$.

[38] The Thatcher [2007] and Meade [2007] block models produce a left-lateral-sense horizontal velocity gradient of magnitude $8-10 \mathrm{~mm} / \mathrm{yr}$ in the vicinity of the Amdo-Sewa fault but this is supported neither by InSAR or GPS 
observations (shown as 3-4 mm/yr in LOS in Figure 6). Our InSAR observations support a right-lateral slip rate of $6 \pm 1 \mathrm{~mm} / \mathrm{yr}$ for the Amdo-Sewa fault, yet this is inconsistent with the mapped kinematics of the CTCFZ. Since the Amdo-Sewa fault has not previously been described, we recommend further study including geological mapping to help resolve the uncertainty of the kinematics and slip rate of this fault zone.

[39] Focused strain gradients, taken as indicative of narrow shear zones at depth, and slip rates in the region of $10 \mathrm{~mm} / \mathrm{yr}$ have been observed for the Altyn Tagh and Xianshuihe faults in previous InSAR studies [e.g., Elliott et al., 2008; Wang et al., 2009]. The Kunlun fault, which we find to slip at $12 \pm 2 \mathrm{~mm} / \mathrm{yr}$, may also exhibit focused strain but our InSAR observations are obscured by postseismic deformation from the 2001 Kokoxili earthquake (Figure 7). However, the Karakoram and Manyi faults [Wang and Wright, 2012; Bell et al., 2011], and the Dongqiao and Beng Co faults studied here (Table 1) have estimated slip rates generally less than $5 \mathrm{~mm} / \mathrm{yr}$.

[40] Molnar and Dayem [2010] note that most fast (with slip rate $\geq 10 \mathrm{~mm} / \mathrm{yr}$ ) strike-slip faults around the world are situated next to strong objects such as cratons or oceanic lithosphere. Numerical experiments with a viscous continuum have shown that strain will tend to localize along the boundary of an embedded strong region and as the amount of strain increases, the width of the shear zone narrows [Dayem et al., 2009]. In the case of Tibet, some major strike-slip faults are situated adjacent to regions inferred to be stronger than the Tibetan lithosphere [Molnar and Tapponnier, 1981; Braitenberg et al., 2003]; the Kunlun fault is situated next to the Qaidam Basin, the Altyn Tagh fault is adjacent to the Tarim Basin, and the south-east segment of the Xianshuihe fault, the most active, is in close proximity to the Sichuan Basin. Molnar and Dayem [2010] summarize the slip rates for these faults to be around $10 \pm 2 \mathrm{~mm} / \mathrm{yr}$. Yet the Karakoram, Manyi, Beng Co, Gyaring Co, Jiali, Dongqiao, and Amdo-Sewa faults are not thought to be situated in proximity to lithospheric strength heterogeneities. Therefore, the hypothesis of Molnar and Dayem [2010] may explain the presence of relatively fast strike-slip faults at the edges of the plateau adjacent to strong lithosphere, and the apparent lack of long, fast strike-slip faults within the plateau interior.

[41] An alternative hypothesis for the lack of focused strain on the faults in central Tibet stems from timedependent deformation associated with the earthquake cycle. In the simple two-layer Savage and Prescott [1978] viscoelastic coupling model for strike-slip faults, strain is diffuse late in the earthquake cycle if the viscoelastic substrate (crust and upper mantle) has a relaxation time that is short compared to the inter-event time. The corollary is that focused strain late in the earthquake cycle only occurs if the relaxation time is equal to or longer than the inter-event time. Although faults in most parts of the world do show focused strain throughout the earthquake cycle [Wright et al., 2013], the lack of focused strain for faults in central Tibet may be consistent with the lithosphere being weak.

[42] In this paper, we have demonstrated how InSAR can be used to address a long-standing problem in HimalayanTibetan tectonics: Is ongoing deformation in the Tibetan Plateau broadly distributed throughout the crust [e.g., England and Houseman, 1986; Flesch et al., 2001; England and Molnar, 2005] or is it concentrated at major faults [e.g., Tapponnier et al., 1982; Avouac and Tapponnier, 1993]? The observations we present here indicate that strain varies smoothly in space without major strain concentration at faults that have previously been mapped as "major" structures (with the exception of the Kunlun fault; Figure 6). Our approach of combining large scenes of SAR data with a velocity field constrained by the available GPS data yields a view of interseismic deformation that is consistent with that GPS data in the Tibetan Plateau. This is important since GPS observations can be frustratingly sparse in many parts of the world, and the method we present here opens up new opportunities to better understand the deformation field in active orogenic systems. Upcoming satellite SAR missions, such as ESA's C-band Sentinel-1, could provide the data coverage of large continental regions at more frequent intervals that will enable operational velocity mapping capabilities. The resulting velocity maps will enable us to locate previously unknown active faults and therefore define more accurately the boundaries of smaller tectonic "blocks."

\section{Conclusions}

[43] 1. We have produced an interseismic rate map of over $1000 \mathrm{~km}$ length using ENVISAT SAR interferometry over an observation period of 6.22 years, which shows the broadscale deformation across the central Tibetan Plateau. The RMS difference between collocated GPS measurements and rate map estimates is less than $1 \mathrm{~mm} / \mathrm{yr}$.

[44] 2. We produce our rate map using a new stacking method implemented in the $\pi-R A T E$ software that incorporates observations from a larger interferogram network in order to increase the number of "coherent" pixels, while also screening for noisy observations that can degrade the rate estimates.

[45] 3. Our rate map observations show that broadscale deformation across the Tibetan Plateau varies smoothly, with strain rates less than $5 \times 10^{-8} \mathrm{yr}^{-1}$ at a measurement length scale of $100 \mathrm{~km}$ (except at the Kunlun fault). Discrepancy between InSAR and GPS observations could be indicative of uplift in central Tibet.

[46] 4. The most striking signal occurs at the E-W striking Kunlun fault, where a strain rate of $18 \pm 4 \times 10^{-8} \mathrm{yr}^{-1}$ is centered on the fault in a narrow zone of $\sim 100 \mathrm{~km}$ width. Following removal of a viscoelastic model that describes the postseismic signal from the 2001 Kokoxili earthquake, we estimate a left-lateral slip rate of $12 \pm 2 \mathrm{~mm} / \mathrm{yr}$ for the Kunlun fault.

[47] 5. By modeling the InSAR rate map observations at mapped conjugate strike-slip faults in central Tibet, we find a right-lateral slip rate of $6 \pm 1 \mathrm{~mm} / \mathrm{yr}$ for the NE-SW striking Amdo-Sewa fault, a left-lateral slip rate range of $1-2 \pm 1 \mathrm{~mm} / \mathrm{yr}$ for the NE-SW striking Dongqiao fault and a right-lateral slip rate range of $1-4 \pm 1 \mathrm{~mm} / \mathrm{yr}$ for the NW-SE striking Beng Co fault.

[48] 6. We find that in a comparison of three methods of mitigating atmospheric phase delay signals in SAR interferograms, the spatiotemporal filter method yields the greatest overall reduction in the magnitude of noise in the interferograms. For our full 51 interferogram network, the RMS maximum covariance drops from $171.1 \mathrm{~mm}^{2}$ to $28.7 \mathrm{~mm}^{2}$ following use of the spatiotemporal filter. 
[49] Acknowledgments. ENVISAT SAR data is copyright of ESA, with some scenes provided under the Dragon-2 initiative. While conducting this research, M.C.G. was supported by a NERC PhD scholarship and T.J.W. was supported by a Royal Society fellowship. H.W. was supported by NSFC (41104016), the State Key Laboratory of Earthquake Dynamics (201306K324), and NCEO/COMET+. Reviews by Peter Molnar and Kip Hodges have greatly improved the manuscript. Thanks to Greg Houseman and John Dawson for reviews of an earlier draft. Thanks to Brendan Meade, John Elliott, Isabelle Ryder, and Cecile Lasserre for providing their result files. Figures were produced using the Generic Mapping Tools software.

\section{References}

Armijo, R., P. Tapponnier, J. L. Mercier, and T. L. Han (1986), Quaternary extension in southern Tibet: Field observations and tectonic implications, J. Geophys. Res., 91 (B14), 13,803-13,872, doi:10.1029/JB091iB14p13803.

Armijo, R., P. Tapponnier, and T. Han (1989), Late cenozoic rightlateral strike-slip faulting in southern Tibet, J. Geophys. Res., 94(B3), 2787-2838, doi:10.1029/JB094iB03p02787.

Avouac, J. P., and P. Tapponnier (1993), Kinematic model of active deformation in central Asia, Geophys. Res. Lett., 20(10), 895-898, doi:10.1029/93GL00128.

Bell, M. A., J. R. Elliott, and B. E. Parsons (2011), Interseismic strain accumulation across the Manyi fault (Tibet) prior to the $1997 \mathrm{Mw} 7.6$ earthquake, Geophys. Res. Lett., 38, L24302, doi:10.1029/2011GL049762.

Berardino, P., G. Fornaro, R. Lanari, and E. Sansosti (2002), A new algorithm for surface deformation monitoring based on small baseline differential SAR interferograms, IEEE T. Geosci. Remote Sens., 40(11), 2375-2383, doi:10.1109/TGRS.2002.803792.

Biggs, J., T. Wright, Z. Lu, and B. Parsons (2007), Multi-interferogram method for measuring interseismic deformation: Denali Fault, Alaska, Geophys. J. Int., 170(3), 1165-1179, doi:10.1111/j.1365-246X.2007. 03415.x.

Braitenberg, C., Y. Wang, J. Fang, and H. T. Hsu (2003), Spatial variations of flexure parameters over the Tibet-Qinghai plateau, Earth Planet Sci. Lett., 205(3-4), 211-224, doi:10.1016/S0012-821X(02)01042-7.

Bürgmann, R., P. A. Rosen, and E. J. Fielding (2000), Synthetic aperture radar interferometry to measure Earth's surface topography and its deformation, Аnnu. Rev. Earth Pl. Sc., 28, 169-209, doi:10.1146/annurev.earth.28.1.169.

Cavalié, O., C. Lasserre, M. P. Doin, G. Peltzer, J. Sun, X. Xu, and Z. K. Shen (2008), Measurement of interseismic strain across the Haiyuan fault (Gansu, China), by InSAR, Earth Planet Sci. Lett., 275(3-4), 246-257, doi:10.1016/j.epsl.2008.07.057.

Cheng, G., and T. Wu (2007), Responses of permafrost to climate change and their environmental significance, Qinghai-Tibet Plateau, J. Geophys. Res. -Ea. Surf., 112, F02S03, doi:10.1029/2006JF000631.

Costantini, M. (1998), A novel phase unwrapping method based on network programming, IEEE T. Geosci. Remote Sens., 36(3), 813-821, doi:10.1109/36.673674

Dawson, J., P. Cummins, P. Tregoning, and M. Leonard (2008), Shallow intraplate earthquakes in Western Australia observed by Interferometric Synthetic Aperture Radar, J. Geophys. Res., 113, B11408, doi:10.1029/2008JB005807.

Dayem, K. E., G. A. Houseman, and P. Molnar (2009), Localization of shear along a lithospheric strength discontinuity: Application of a continuous deformation model to the boundary between Tibet and the Tarim Basin, Tectonics, 28, TC3002, doi:10.1029/2008TC002264.

Elliott, J. R., J. Biggs, B. Parsons, and T. J. Wright (2008), InSAR slip rate determination on the Altyn Tagh Fault, northern Tibet, in the presence of topographically correlated atmospheric delays, Geophys. Res. Lett., 35, L12309, doi:10.1029/2008GL033659.

Elliott, J. R., R. J. Walters, P. C. England, J. A. Jackson, Z. Li, and B. Parsons (2010), Extension on the Tibetan plateau: Recent normal faulting measured by InSAR and body wave seismology, Geophys. J. Int., 183(2), 503-535, doi:10.1111/j.1365-246X.2010.04754.x.

England, P., and G. Houseman (1986), Finite strain calculations of continental deformation 2. Comparison with the India-Asia collision zone, J. Geophys. Res., 91(B3), 3664-3676, doi:10.1029/ JB091iB03p03664.

England, P., and P. Molnar (2005), Late Quaternary to decadal velocity fields in Asia, J. Geophys. Res., 110, B12401, doi:10.1029/ 2004JB003541.

Farr, T. G., et al. (2007), The shuttle radar topography mission, Rev. Geophys., 45(2), RG2004, doi:10.1029/2005RG000183.

Ferretti, A., C. Prati, and F. Rocca (2001), Permanent scatterers in SAR interferometry, IEEE T. Geosci. Remote Sens., 39(1), 8-20, doi:10.1109/ 36.898661 .
Flesch, L. M., A. J. Haines, and W. E. Holt (2001), Dynamics of the India-Eurasia collision zone, J. Geophys. Res., 106(B8), 16,435-16,460, doi:10.1029/2001JB000208.

Freymueller, J. T., Y. Fu, Q. Wang, S. Yang, C. Xu, and G. Chen (2010), How rapidly is the Tibetan Plateau rising, and what fraction of that is tectonic?Abstract T41D-03 presented at 2010 Fall Meeting, AGU, San Francisco, Calif., December 3-17, 2010.

Gan, W., P. Zhang, Z.-K. Shen, Z. Niu, M. Wang, Y. Wan, D. Zhou, and J. Cheng (2007), Present-day crustal motion within the Tibetan Plateau inferred from GPS measurements, J. Geophys. Res., 112, B08416, doi:10.1029/2005JB004120.

Goldstein, R. M., and C. L. Werner (1998), Radar interferogram filtering for geophysical applications, Geophys. Res. Lett., 25(21), 4035-4038, doi:10.1029/1998GL900033.

Gourmelen, N., F. Amelung, and R. Lanari (2010), Interferometric synthetic aperture radar-GPS integration: Interseismic strain accumulation across the Hunter Mountain fault in the eastern California shear zone, J. Geophys. Res., 115, B09408, doi:10.1029/2009JB007064.

Hammond, W. C., G. Blewitt, and C. Kreemer (2011), Block modeling of crustal deformation of the northern Walker Lane and Basin and Range from GPS velocities, J. Geophys. Res., 116, B04402, doi:10.1029/2010JB007817.

Hanssen, R. F. (2001), Radar Interferometry-Data Interpretation and Error Analysis, Kluwer Academic Publishers, Netherlands.

Jolivet, R., R. Cattin, N. Chamot-Rooke, C. Lasserre, and G. Peltzer (2008), Thin-plate modeling of interseismic deformation and asymmetry across the Altyn Tagh fault zone, Geophys. Res. Lett., 35, L02309, doi:10.1029/2007GL031511.

Jolivet, R., R. Grandin, C. Lasserre, M.-P. Doin, and G. Peltzer (2011), Systematic InSAR tropospheric phase delay corrections from global meteorological reanalysis data, Geophys. Res. Lett., 38, L17311, doi:10.1029/2011GL048757.

Jolivet, R., C. Lasserre, M. P. Doin, S. Guillaso, G. Peltzer, R. Dailu, J. Sun, Z.-K. Shen, and X. Xu (2012), Shallow creep on the Haiyuan Fault (Gansu, China) revealed by SAR interferometry, J. Geophys. Res., 117, B06401, doi:10.1029/2011JB008732.

Kinoshita, Y., M. Furuya, T. Hobiger, and R. Ichikawa (2013), Are numerical weather model outputs helpful to reduce tropospheric delay signals in InSAR data? J. Geodesy., 87, 267-277, doi:10.1007/s00190-012-0596-x.

Kruskal, J. B. (1956), On the shortest spanning subtree of a graph and the traveling salesman problem, Proc. Am. Math. Soc., 7(1), 48-50, doi:10.1090/S0002-9939-1956-0078686-7.

Lasserre, C., G. Peltzer, F. Crampe, Y. Klinger, J. Van der Woerd, and P. Tapponnier (2005), Coseismic deformation of the $2001 M_{w} 7.8$ Kokoxili earthquake in Tibet, measured by synthetic aperture radar interferometry, J. Geophys. Res., 110, B12408, doi:10.1029/2004JB003500.

Lasserre, C., et al. (2007), Interseismic strain across the Altyn Tagh and Haiyuan faults at the northern edge of the Tibetan plateau, measured by space geodesy, Geophys. Res. Abstr., 9, 10,102.

Lohman, R. B., and M. Simons (2005), Locations of selected small earthquakes in the Zagros mountains, Geochem. Geophys. Geosyst., 6, Q03001, doi:10.1029/2004GC000849.

Meade, B. J. (2007), Present-day kinematics at the India-Asia collision zone, Geology, 35(1), 81-84, doi:10.1130/G22924A.1.

Meade, B. J., and B. H. Hager (2005), Block models of crustal motion in southern California constrained by GPS measurements, J. Geophys. Res, 110, B03403, doi:10.1029/2004JB003209.

Molnar, P., and W.-P. Chen (1983), Focal depths and fault plane solutions of earthquakes under the Tibetan plateau, J. Geophys. Res., 88(B2), 1180-1196, doi:10.1029/JB088iB02p01180.

Molnar, P., and K. E. Dayem (2010), Major intracontinental strike-slip faults and contrasts in lithospheric strength, Geosphere, 6(4), 444-467, doi:10.1130/GES00519.1.

Molnar, P., and P. Tapponnier (1975), Cenozoic tectonics of Asia: Effects of a continental collision, Science, 189, 419-426, doi:10.1126/ science. 189.4201 .419$.

Molnar, P., and P. Tapponnier (1978), Active tectonics of Tibet, J. Geophys. Res., 83(B11), 5361-5375, doi:10.1029/JB083iB11p05361.

Molnar, P., and P. Tapponnier (1981), A possible dependence of tectonic strength on the age of the crust in Asia, Earth Planet Sci. Lett., 52(1), 107-114, doi:10.1016/0012-821X(81)90213-2.

Peltzer, G., F. Crampe, S. Hensley, and P. Rosen (2001), Transient strain accumulation and fault interaction in the Eastern California shear zone, Geology, 29(11), 975-978, doi:10.1130/00917613(2001)029<0975:TSAAFI >2.0.CO;2.

Rosen, P. A., S. Hensley, I. R. Joughin, F. K. Li, S. N. Madsen, E. Rodriguez, and R. M. Goldstein (2000), Synthetic aperture radar interferometry, Proc. IEEE, 88(3), 333-382, doi:10.1109/5.838084.

Ryder, I., R. Bürgmann, and F. Pollitz (2011), Lower crustal relaxation beneath the Tibetan Plateau and Qaidam Basin following the 2001 
Kokoxili earthquake, Geophys. J. Int., 187, 613-630, doi:10.1111/j.1365246X.2011.05179.X.

Savage, J., and R. O. Burford (1973), Geodetic determination of relative plate motion in central California, J. Geophys. Res., 78(B5), 832-845, doi:10.1029/JB078i005p00832.

Savage, J., and W. H. Prescott (1978), Asthenosphere readjustment and the earthquake cycle, J. Geophys. Res., 83(B7), 3369-3376, doi:10.1029/JB083iB07p03369.

Tapponnier, P., G. Peltzer, A. Y. Le Dain, R. Armijo, and P. Cobbold (1982), Propagating extrusion tectonics in Asia: New insights from simple experiments with plasticine, Geology, 10, 611-616, doi:10.1130/00917613(1982)10.

Taylor, M., and G. Peltzer (2006), Current slip rates on conjugate strikeslip faults in central Tibet using synthetic aperture radar interferometry, J. Geophys. Res., 111, B12402, doi:10.1029/2005JB004014.

Taylor, M., and A. Yin (2009), Active structures of the Himalayan-Tibetan orogen and their relationships to earthquake distribution, contemporary strain field, and Cenozoic volcanism, Geosphere, 5(3), 199-214, doi:10.1130/GES00217.1.

Taylor, M., A. Yin, F. J. Ryerson, P. Kapp, and L. Ding (2003), Conjugate strike-slip faulting along the Bangong-Nujiang suture zone accommodates coeval east-west extension and north-south shortening in the interior of the Tibetan Plateau, Tectonics, 22(4), 1044, doi:10.1029/2002TC001361.
Thatcher, W. (2007), Microplate model for the present-day deformation of Tibet, J. Geophys. Res., 112, B01401, doi:10.1029/2005JB004244.

Wang, H., and T. J. Wright (2012), Satellite geodetic imaging reveals internal deformation of western Tibet, Geophys. Res. Lett., 39, L07303, doi:10.1029/2012GL051222.

Wang, H., T. J. Wright, and J. Biggs (2009), Interseismic slip rate of the northwestern Xianshuihe fault from InSAR data, Geophys. Res. Lett., 36, L03302, doi:10.1029/2008GL036560.

Wang, H., T. J. Wright, Y. Yu, H. Lin, L. Jiang, C. Li, and G. Qiu (2012), InSAR reveals coastal subsidence in the Pearl River Delta, China, Geophys. J. Int., 191(3), 1119-1128, doi:10.1111/j.1365246X.2012.05687.x.

Wright, T. J., B. Parsons, and E. J. Fielding (2001), Measurement of interseismic strain accumulation across the North Anatolian Fault by satellite radar interferometry, Geophys. Res. Lett., 28(10), 2117-2120, doi:10.1029/2000GL012850.

Wright, T. J., B. Parsons, P. C. England, and E. J. Fielding (2004), InSAR observations of low slip rates on the major faults of western Tibet, Science, 305(5681), 236-239, doi:10.1126/science. 1096388.

Wright, T. J., J. Elliott, H. Wang, and I. Ryder (2013), Earthquake cycle deformation and the Moho: Implications for the rheology of continental lithosphere, Tectonophysics, doi:10.1016/j.tecto.2013.07.029, in press. 